Rev. Saude públ., S. Paulo

8: 51-62, 1974

\title{
ASPECTOS EPIDEMIOLÓGICOS DA CÁRIE DENTAL EM ESCOLARES BRANCOS E NÃO BRANCOS DE AMBOS OS SEXOS INTERNOS EM SETE ORFANATOS DA CIDADE DE SÃO PAULO, BRASIL, EM $1972 *$
}

Roberto Augusto CASTELLANOS **

\begin{tabular}{ll|} 
RSPU-B/203 \\
\hline
\end{tabular}

Castellanos, R. A. - Aspectos epidemiológicos da cárie dental em escolares brancos e não brancos de ambos os sexos internos em sete orfanatos da cidade de São Paulo, Brasil, em 1972. Rev. Saúde públ., S. Paulo, 8: $51-62,1974$.

RESUMo: Foi realizado um levantamento epidemiológico de cárie dental em 860 escolares de ambos os sexos, de 7 a 12 anos, de cor branca e não branca, internos em sete orfanatos da cidade de $\mathrm{S} \tilde{a} \circ$ Paulo, com o objetivo de verificar se em criancas brancas e näo-brancas, vivendo nas mesmas condições ambientais, era possivel detectar diferenças na experiência da cárie. Neste estudo, foram controladas variáveis de grande importancia em relaçäo à cárie dental, tais como dieta e freqüência da ingestão de substâncias acucaradas durante, ou entre as refeicōes. Foram estudadas relaçōes entre idade, sexo e cor das crianças com os valores do indice CPO, com o número de dentes permanentes irrompidos e com os valores médios de dentes permanen. tes atacados por cárie por 100 dentes irrompidos. Os resultados obtidos mostram que os brancos nâa apresentam prevalência de cárie dental estatisticamente maior do que os não brancos, na dentiçäo permanente.

Unitermos: Cárie dental*; Escolares, São Paulo (Brasil)*; Indice CPO médio*; Inquérito epidemiológico.

\section{I N T R O D U A O}

Os estudos para determinar a forma de como uma doença se manifesta em grupos populacionais, geralmente relacionam características tais como idade, sexo, cor, raça e outros fatores como ocupação, hábitos alimentares, água de beber, clima e nível sócio-econômico.

Em relação às características raça $e$ cor, vários autores relatam ter encontrado maior prevalência de cárie em indivíduos brancos, quando comparados com indivíduos negros, por idade e sexo entre os quais KNUtson ${ }^{9}$ (1944), Sebelius ${ }^{13}$ (1944), Blayney \& Hill ${ }^{3}$ (1967), Souza et al. ${ }^{14}$ (1967), LitTLETON et al. ${ }^{10}$ (1970) e Kelly \& Scanlon $^{6}$ (1971). Outros

- Trabalho apresentado à Faculdade de Saúde Pública da USP, para a obtenção do título de Mestre em Saúde Pública.

* Do Departamento de Prática de Saúde Pública da Faculdade de Saúde Pública da USP - Av. Dr. Arnaldo, 715 - São Paulo, SP — Brasil. 
CASTEllanos, R. A. - Aspectos epidemiológicos da cárie dental em escolares brancos e não brancos de ambos os sexos internos em sete orfanatos da cidade de São Paulo, Brasil, em 1972. Rev. Saúde pübl., S. Paulo, 8:51-62, 1974.

\section{TABELA 1}

Número de crianças examinadas nos orfanatos da cidade de são Paulo, segundo idade, sexo e cor - São Paulo, 1972

\begin{tabular}{|c|c|c|c|c|c|c|c|c|c|}
\hline \multirow[b]{2}{*}{ Idade } & \multicolumn{3}{|c|}{ Brancas } & \multicolumn{3}{|c|}{ Não brancas } & \multicolumn{3}{|c|}{ Total } \\
\hline & M & $\mathrm{F}$ & Ambas & $\mathrm{M}$ & $F$ & Ambas & M & $F$ & Ambas \\
\hline 7 & 47 & 22 & 69 & $58 *$ & 28 & 86 & 105 & 50 & 155 \\
\hline 8 & 48 & 15 & 63 & 37 & 10 & 47 & 85 & 25 & 110 \\
\hline 9 & $60^{*}$ & 19 & 79 & 49 & 21 & 70 & 109 & 40 & 149 \\
\hline 10 & $56 *$ & 15 & 71 & $73^{*}$ & 28 & 101 & 129 & 43 & 172 \\
\hline 11 & $55 *$ & 13 & 68 & $58^{*}$ & 23 & 81 & 113 & 36 & 149 \\
\hline 12 & 30 & 17 & 47 & $59 *$ & 19 & 78 & 89 & 36 & 125 \\
\hline $7-12$ & 296 & 101 & 397 & 334 & 129 & 463 & 630 & 230 & 860 \\
\hline
\end{tabular}

* Nestes grupos etários foi possível controlar o erro de 2.a espécie.

autores CReighto: ${ }^{4}$ (1969), e BAGRAMIAN \& RuSSELL ${ }^{1}$ (1971) não encontraram diferenças significantes que demonstrassem maior experiência desta lesão na população branca.

Apesar de existir maior número de trabalhos indicando menor susceptibilidade ao ataque de cárie por parte da população negra, o problema permanece controvertido, mesmo porque neste campo ainda não foram esclarecidas as causas que possam ser responsáveis por tal fato, admitindo-se que um fator hereditário ou genético possa ser o maior responsável. Entretanto, os autores que não encontraram diferenças em ambos os grupos acham que esse fator hereditário foi superado, e que a dieta similar para eles poderia ser o responsável pelo fato das crianças negras de seus estudos terem alcançado as brancas quanto à suceptibilidade da cárie dental.

Interessados em verificar se em crianças brasileiras brancas e não brancas, vivendo nas mesmas condições ambientais, era possível detectar diferenças na experiência de cárie dental, propusemos-nos a realizar um levantamento epidemiológico. Escolhemos, com esse fim, escolares de ambos os sexos de cor branca e não bran- ca, internos em orfanatos da cidade de São Paulo.

\section{MATERIAL E MÉTODOS}

A população a examinar era constituída por 860 escolares de ambos os sexos de cor branca e não branca, internadas em 7 orfanatos da cidade de São Paulo, no ano de 1972 (Tabela 1).

Inicialmente, pensou-se em obter uma amostra para cada grupo etário, sexo e cor, segundo os seguintes critério: detectar diferenças de pelo menos 0,5 desviospadrão, $\alpha$ (tamanho do erro de 1." espécie) igual a 0,05 e $\beta$ (tamanho do erro de 2." espécie) igual a 0,10 . Usando o gráfico de curva operacional (Berquo? 1968) para estes critérios o tamanho da amostra requerida foi de 50 indivíduos em cada grupo etário por sexo e cor.

Nem sempre foi possivel obter o tamanho necessário. Assim, optou-se por examinar toda a população existente naqueles orfanatos entre 7 e 12 anos.

\subsection{Classificação das crianças}

$\mathrm{O}$ autor, utilizando algumas caracterís- 
CASTEllanos, R. A. - Aspectos epidemiológicos da cárie dental em escolares brancos e não brancos de ambos os sexos internos em sete orfanatos da cidade de São Paulo, Brasil, em 1972. Rev. Saúde públ., S. Paulo, 8: 51-62, 1974.

ticas descritas por NesturJ ${ }^{12}$ que identifica as raças branca e negra, e a característica cor da gengiva (GLICKMAN ${ }^{5}$, 1958), classificou as crianças em:

2.1.1. Crianças brancas: as que reuniam as seguintes características: a) pele branca; b) cabelo liso ou ondulado fino (de loiro a negro); c) nariz estreito e proeminente; d) lábios finos (ou de espessura mediana); e) gengiva cor rósea (com suas variações normais devidas à queratinização e vascularização).

2.1.2. Crianças näo brancas: a) pele castanho escura ou negra; b) cabelo ondulado, encarapinhado ou em anel, geralmente escuro; c) nariz largo ou achatado (na maioria dos casos); d) lábios grossos e salientes (na maioria dos casos); e) gengiva pigmentada pelo acúmulo de melanina.

Devemos ainda observar que pela dificuldade de classificação de indivíduos por características raciais em um país de tão alto índice de miscigenação como é o Brasil, em certos casos a seleção foi feita segundo a predominância de determinados traços.

\subsection{Variáveis observadas}

Foram utilizadas como variáveis independentes a idade, sexo e cor das crianças e como variáveis dependentes os valores dos índices CPO (KLEIN \& PALMER ${ }^{8}$, 1937); o número de dentes permanentes irrompidos e a média de dentes permanentes atacados por cárie por 100 dentes irrompidos.

\subsection{Processo do levantamento}

Os critérios dos índices, o código de registro dos dados, o método de exame e a ficha empregada foram os utilizados pela disciplina de Odontologia Sanitária do Departamento de Prática de Saúde da Faculdade de Saúde Pública da USP, para realizar este tipo de levantamento ${ }^{11}$.
Uma calibração prévia ao levantamento foi realizada em crianças similares ao deste estudo.

\subsection{Alimentação}

Cada instituição forneceu uma relação da dieta das crianças durante a semana relativa à época do levantamento, havendo-se feito também observações pessoais com a finalidade de constatar se havia homogeneidade a esse respeito entre as diversas instituições. A pequena variação entre estas facilitou seu agrupamento assim: pela manhã, leite ou café com leite e pão com manteiga ou doce; no almoço, arroz e feijão (diariamente), verduras (geralmente), carnes, ovos ou macarronada (alternadamente); no jantar, sopas de diversos tipos; no lanche (de manhã ou à tarde), fruta ou pão com doce (alternadamente); como sobremesa, arroz-doce, mingau, creme ou frutas.

\subsection{Tratamento estatistico}

A descrição dos resultados foi feita através de médias e desvios-padrão e a análise estatística por meio de testes da diferença entre duas médias, utilizando-se

a estatística $t=\frac{x_{1}-x_{2}}{\sqrt{G^{2}\left(\frac{1}{n_{1}}+\frac{1}{n_{2}}\right)}}$

com distribuição $t$ de "student" com $\mathrm{n}_{1}+\mathrm{n}_{2}{ }^{-2}$ graus de liberdade (Berquo ${ }^{2}$, 1968), onde:

$\bar{x}_{1}=$ média amostral dos brancos

$\overline{\mathrm{x}}_{2}=$ média amostral dos não brancos

\subsection{Hipóteses}

Em cada grupo etário, por sexo e cor, foram testadas as seguintes hipóteses:

$\mathrm{H}_{0}=$ prevalência de cárie dental em brancos $=$ prevalência em não brancos. 
CASTELlanos, R. A. - Aspectos epidemiológicos da cárie dental em escolares brancos e não brancos de ambos os sexos internos em sete orfanatos da cidade de Săo Paulo, Brasil, em 1972. Rev. Saúde públ., S. Paulo, 8: 51-62, 1974.

TABELA 2

Número e porcentagem de crianças sem cárie, de cor branca e não branca, do sexo masculino, segundo a ldade, internados em orfanatos da cidade de săo Paulo, 1972

\begin{tabular}{|c|c|c|c|c|}
\hline \multirow[b]{2}{*}{ Idade } & \multicolumn{2}{|c|}{ Brancas } & \multicolumn{2}{|c|}{ Não brancas } \\
\hline & Número & Porcentagem & Número & Porcentagem \\
\hline 7 & 24 & 51,06 & 39 & 67,24 \\
\hline 8 & 17 & 35,42 & 14 & 37,84 \\
\hline 9 & 12 & 20,00 & 17 & 34,69 \\
\hline 10 & 11 & 19,64 & 18 & 24,66 \\
\hline 11 & $\mathbf{5}$ & 9,09 & $\mathbf{5}$ & 8,62 \\
\hline 12 & 2 & 6,67 & 5 & 8,47 \\
\hline $7-12$ & 71 & 32,99 & 98 & 43,58 \\
\hline
\end{tabular}

$\mathrm{H}_{1}=$ prevalência de cárie dental em brancos $>$ prevalência em não brancos.

E para dentes permanentes irrompidos, as hipóteses testadas foram:

$\mathrm{H}_{0}=$ número de dentes permanentes irrompidos em não brancos $=$ número de dentes em brancos.

$\mathrm{H}_{1}=$ número de dentes permanentes irrompidos em não brancos $>$ que número de dentes em brancos.

Considerou-se cada teste monocaudal como significante quando o valor observado de $(t)$ limitasse uma área correspondendo a uma probabilidade igual ou menor do que 0,05 .

\section{RESULTADOS}

\subsection{Dentes permanentes}

\subsubsection{Crianças sem cárie}

0 percentual de crianças isentas de cárie resulta ser maior para o grupo das não brancas, sendo que mais de um terço $(43,58 \%)$ do sexo masculino e um terço $(32,97 \%)$ do sexo feminino apresentaram esta condição (Tabelas 2 e 3 ).

\subsubsection{Dentes atacados por cárie}

Nas Tabelas 4 e 5 apresentam-se os valores médios do índice CPO nos diferentes grupos de crianças conforme a idade e sexo, observando-se um aumento do número de dentes CPO concomitantemente com a idade. Assim como também os grupos etários por sexo e cor em que as diferenças foram significantes a nível de 0,05 .

\subsubsection{Dentes irrompidos}

Nas Tabelas 6 e 7 nota-se que os valores médios de dentes irrompidos entre crianças brancas e não brancas são de forma geral maiores para estas últimas em ambos os sexos; sendo que a diferença somente foi significante nas idades de 7 , 8 e 10 anos para o sexo masculino.

\subsubsection{Dentes atacados por cárie por 100 dentes irrompidos}

Nas Tabelas 8 e 9 apresenta-se o número médio de dentes atacados por cárie 
CASTELlaNOS, R. A. - Aspectos epidemiológicos da cárie dental em escolares brancos e năo brancos de ambos os sexos internos em sete orfanatos da cidade de São Paulo, Brasil, em 1972. Rev. Saude públ., S. Paulo, 8: 51-62, 1974.

TABEIA 3

Número e porcentagem de crianças sem cárie, de cor branca e não branca, do sexo feminino, segundo a idade, internadas em orfanatos da cldade de São Paulo, 1972

\begin{tabular}{|c|c|c|c|c|}
\hline \multirow[b]{2}{*}{ Idade } & \multicolumn{2}{|c|}{ Brancas } & \multicolumn{2}{|c|}{ Năo brancas } \\
\hline & Número & Porcentagem & Número & Porcentagem \\
\hline 7 & 11 & 50,00 & 16 & 57,14 \\
\hline 8 & 9 & 60,00 & 7 & 70,00 \\
\hline 9 & 6 & 31,58 & 8 & 38,09 \\
\hline 10 & 1 & 6,67 & 9 & 32,14 \\
\hline 11 & - & - & 6 & 26,09 \\
\hline 12 & 1 & 5,88 & 2 & 10,53 \\
\hline $7-12$ & 28 & 28,79 & 66 & 32,97 \\
\hline
\end{tabular}

em 'relação ao número médio de dentes irrompidos por idade, sexo e cor.

\section{D I S U S S A}

\subsection{Dentes permanentes}

\subsubsection{Dentes atacados por cárie}

Apesar de se observar diferenças nos vários grupos etários, com $\mathrm{CPO}$ médio maior nas crianças brancas, somente na idade de 9 e 10 anos, nos meninos, e de 11 , nas meninas houve diferenças significantes a nível de 0,05.

Estes resultados estão de acordo com os relatados por CREIGHToN 4 (1969) e $\mathrm{B}_{\mathrm{A}-}$ GRAMIAN \& RuSSELL ${ }^{1}$ (1971) que não encontraram diferenças significantes que demonstrassem maior experiência de cárie dental na população branca. Assim, por exemplo, CREIGHTON ${ }^{4}$ (1969) relata que no grupo de crianças por ele examinadas, unicamente nas do sexo masculino da 1." série o índice CPO foi similar, sendo nos restantes grupos consistentemente maior para as negras, quando sexo e série foram mantidas como constantes.

Outros autores encontraram maior pre- valência de cárie em indivíduos brancos quando comparados com indivíduos negros. Seus resultados foram apresentados como: a) ligeiras diferenças (KELLY \& SCANLON ${ }^{8}$, 1971) ; b) amplas variaçōes (KNutson ${ }^{8}, 1944$ e LitTleton $\left.{ }^{~}, 1970\right)$; e c) diferenças significantes (SEbelius ${ }^{13}$, 1944; BLAYNEY \& Hill ${ }^{3}$, 1967; e Souza et al. ${ }^{14}, 1967$ ).

SouzA et al. ${ }^{14}$ (1967) examinaram 4 grupos etários $(8,10,11$ e 12 anos), sendo que os valores médios CPO foram maiores para as crianças não brancas que para as brancas e diferentemente significantes nas idades de 8,11 e 12 anos.

Comparando esses resultados com os nossos, verificamos que os valores médios CPO para ambos os grupos de crianças por idade e cor são maiores que os nossos.

Ressaltamos, no entanto, que os estudos não são comparáveis, desde que eles não observaram as idades de 7 a 9 anos e a diferença por sexo dos grupos estudados.

Aliás, restriçōes também podem ser feitas para comparação com outros trabalhos mencionados $1,3,4,9,10,18$ em que a apresentação dos resultados corresponde a outros grupos etários, a agrupamento de 
CASTEllanos, R. A. - Aspectos epidemiológicos da cárie dental em escolares brancos e não brancos de ambos os sexos internos em sete orfanatos da cidade de São Paulo, Brasil, em 1972. Rev. Saúde puibl., S. Paulo, 8: 51-62, 1974.

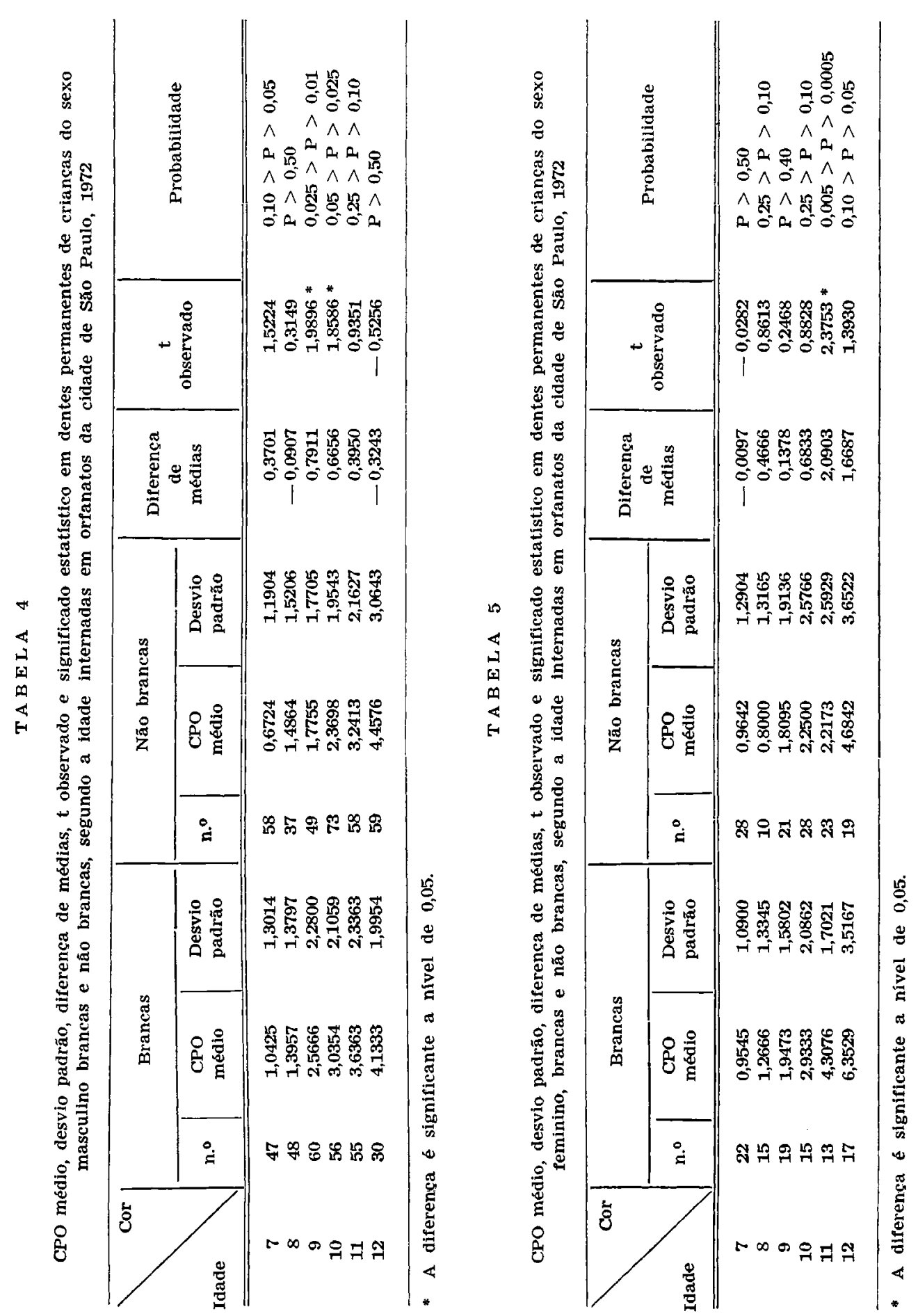


CASTEllaNOS, R. A. - Aspectos epidemiológicos da cárie dental em escolares brancos e não brancos de ambos os sexos internos em sete orfanatos da cidade de São Paulo, Brasil, em 1972. Rev. Saude puibl., S. Paulo, 8: 51-62, 1974.

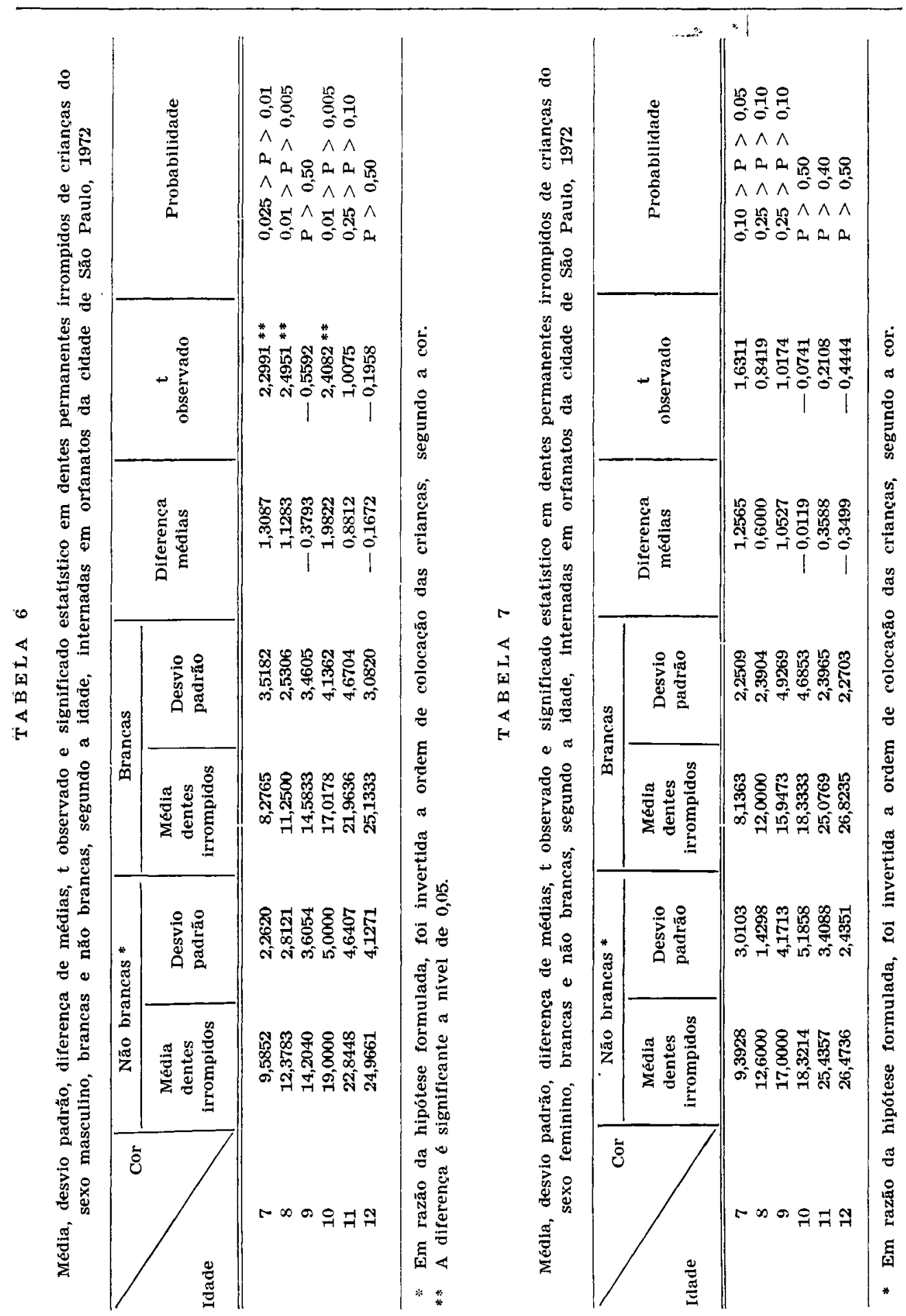


CASTEllanos, R. A. - Aspectos epidemiológicos da cárie dental em escolares brancos e não brancos de ambos os sexos internos em sete orfanatos da cidade de São Paulo, Brasll, em 1972. Rev. Saúde públ., S. Paulo, 8: 51-62, 1974.

\section{TABELA 8}

Médias de dentes permanentes atacados por cárie ( $\overline{\mathrm{CPO}}$ ) para cada 100 dentes irrompidos, e respectiva diferença, de crianças do sexo masculino, brancas e não brancas, segundo a idade, internadas em orfanatos da cidade de São Paulo, 1972

\begin{tabular}{|c|c|c|c|}
\hline Idade & $\begin{array}{l}\text { Brancas } \\
\overline{\mathrm{CPO}} / 100 \text { dentes } \\
\text { irrompidos }\end{array}$ & $\begin{array}{l}\text { Não brancas } \\
\text { CPO/100 dentes } \\
\text { Irrompidos }\end{array}$ & $\begin{array}{l}\text { Diferenca } \\
\overline{\mathrm{CPO}} / 100 \text { dentes } \\
\text { irrompidos }\end{array}$ \\
\hline 7 & 12,59 & 7,01 & 5,58 \\
\hline 8 & 12,41 & 12,01 & 0,40 \\
\hline 9 & 17,60 & 12,50 & 5,10 \\
\hline 10 & 17,84 & 12,47 & 5,37 \\
\hline 11 & 16,56 & 14,19 & 2,37 \\
\hline 12 & 16,45 & 17,85 & $-1,41$ \\
\hline
\end{tabular}

TABEIA 9

Médias de dentes permanentes atacados por cárie ( $\overline{\mathrm{CPO}}$ ) para cada 100 dentes irrompldos, e respectiva diferença, de crianças do sexo feminino, brancas e não brancas, segundo a idade, internadas em orfanatos da cidade de São Paulo, 1972

\begin{tabular}{r|c|c|c}
\hline Idade & $\begin{array}{c}\text { Brancas } \\
\overline{\mathrm{CPO}} / 100 \text { dentes } \\
\text { Irrompidos }\end{array}$ & $\begin{array}{c}\text { Não brancas } \\
\mathbf{C P O} / 100 \text { dentes } \\
\text { irrompidos }\end{array}$ & $\begin{array}{c}\text { Diferenca } \\
\overline{\mathrm{CPO}} / 100 \text { dentes } \\
\text { irrompidos }\end{array}$ \\
\hline 7 & 11,73 & 10,27 & 1,46 \\
8 & 10,55 & 6,35 & 4,20 \\
9 & 12,21 & 10,64 & 1,57 \\
11 & 16,00 & 12,28 & 9,72 \\
12 & 18,10 & 8,72 & 5,38 \\
\hline
\end{tabular}

diferentes idades, a utilização de outros critérios para o registro de cárie, ou mesmo de outras variáveis.

\subsubsection{Dentes irrompidos}

No presente estudo as crianças não brancas apresentaram, de maneira geral, por sexo e idade, um número médio de dentes irrompidos maior que o das brancas. Entretanto, somente no sexo masculino e nas idades de 7,8 e 10 anos as diferenças foram significantes a nível de 0,05 . O relacionamento destes resultados com os valores de cárie observados nesses mesmos grupos etários, menores para as crianças não brancas, e a significante diferença na idade de 10 anos, poderia levar a pensar em uma maior susceptibilidade ao ataque de cárie de parte das crianças brancas, neste grupo etário.

A observação da precocidade na erupção dos dentes dos negros com maior precisão foi feita por STEGgerda \& HiLl ${ }^{15}$. (1942) que durante 10 anos examinaram 4 grupos raciais e observaram que no grupo formado por crianças negras, os dentes irrompiam mais cedo que no grupo das brancas, sendo as diferenças na sua maioria significantes.

KeLIy \& SCALON ${ }^{\circ}$ (1971) também re- 
CASTELlaNos, R. A. - Aspectos epidemiológicos da cárie dental em escolares brancos e não brancos de ambos os sexos internos em sete orfanatos da cidade de São Paulo, Brasil, em 1972. Rev. Satide pribl., S. Paulo, 8: 51-62, 1974.

latam que nas crianças americanas os dentes das negras irrompem mais cedo que os dentes das brancas, por idade e sexo. Baseados neste fato e na observação de valores médios CPO menores nas crianças negras, sugerem que os dentes destas são menos susceptíveis ao ataque de cárie. Utilizam ainda como argumento os resultados do levantamento de cárie dental, realizado em 1962 na população adulta desse mesmo país, o qual mostrou que as mesmas diferenças prevaleciam e, de forma geral, maiores e mais consistentes que as observadas nas crianças.

SouZA et al. ${ }^{14}$ (1967) observaram valores semelhantes no número médio de dentes permanentes irrompidos por grupo etário e cor, à exceção da idade de 10 anos em que as crianças não brancas apresentaram um número médio maior. Daí concluiram que a maior prevalência de cárie nas crianças brancas não é devido a uma precocidade na erupção dentária nestas.

Devemos ainda assinalar a importância de considerar o número de dentes irrompidos quando se comparam valores médios de cárie em grupos populacionais para se dar um maior significado à comparação. Desta maneira, é possível estabelecer, ao constatar diferenças, se são devidas a algum fator ligado à característica em estudo, ou a uma maior susceptibilidade à cárie de um dos grupos em relação ao outro, ou se a diferença ocorre apenas porque existe um maior número de dentes expostos ao risco de ataque desta lesão.

\subsubsection{Dentes atacados por cárie por 100 dentes irrompidos}

Esta proporção que poderíamos denominar como "risco médio do ataque de cárie por grupo etário por 100 dentes irrompidos", no presente trabalho, é maior para as crianças brancas que para as não brancas. Ela indica quantos dentes a mais estariam sujeitos ao risco do ataque e leva em consideração cárie e dentes irrompidos, pelo que achamos seria conveniente sua utilização quando se estabelecem comparaçōes como, por exemplo, por idade, sexo, cor, ou raça. Esta proporção, a nosso entender, parece ser um indicador com bastante utilidade ao lado do CPO médio.

$\mathrm{Na}$ literatura consultada apenas KELLY \& Scanlon ${ }^{6}$ (1971) fazem alguma referência ao número de dentes $\mathrm{CPO}$ por 100 dentes permanentes irrompidos.

\subsubsection{Crianças sem cárie}

Neste estudo constatamos que o maior percentual de crianças sem cárie corresponde ao grupo de crianças não brancas. Similares resultados são assinalados por KNUTSON $^{9}$ (1944) com valores semelhantes aos nossos em relação às crianças brancas e maiores no que respeita às não brancas.

A maioria dos autores concorda com o fato de que não existe evidência sobre a causa responsável pela menor susceptibilidade à cárie de parte dos negros.

Sebelius ${ }^{13}$ (1944) diz que pela literatura consultada, possivelmente hereditariedade e imunidade devem ter efeitos diferentes e poderia ser esta uma das razões de que certos grupos raciais tenham diferentes experiências de cárie.

CReighton * (1969) pensa na hipótese de que a dieta (similar nas crianças caucasianas e negras de seu estudo), a falta de informação no que se relaciona à saúde bucal e o menor acesso a tratamento preventivo por parte das crianças negras (resultado de desvantagens econômicas e educacionais) seriam determinantes na experiência de cárie dental e parcialmente responsáveis pelo fato destas crianças terem alcançado as caucasianas quanto à susceptibilidade da cárie dental. 
CASTELlanos, R. A. - Aspectos epidemiológicos da cárie dental em escolares brancos e não brancos de ambos os sexos internos em sete orfanatos da cidade de Săo Paulo, Brasil, em 1972. Rev. Saúde públ., S. Paulo, 8: 51-62, 1974.

Littleton et al. ${ }^{10}$ (1970) utilizaram outras variáveis que podem estar associadas com diferenças na experiência de cárie dental entre caucasianas e negras. Culturas de material de placa dental para medir presença de estreptococos específicos que induzem à cárie dental em hamster, a formação de polisacarídeos extracelulares produzidos por esses e outros tipos de estreptococos na placa dental e a medição do seu $\mathrm{pH}$ antes e depois da adição de sacarose, não ofereceram diferenças significantes entre ambos os grupos.

Esses autores também entrevistaram as crianças quanto a hábitos alimentares, e as negras relataram comer mais e com maior freqüência alimentos açucarados. Em relação ao índice de higiene oral, os caucasianos apresentaram valores ligeiramente maiores no índice de indutos e os negros valores do índice de cálculo significativamente maiores.

No entanto, esses autores não chegaram a uma conclusão exata e por essa razão estão realizando estudos adicionais sobre a ocorrência da cárie em ambos os grupos.

Bagramian \& Russell ${ }^{1}$ (1971) concluem que o fator genético responsável no passado pela baixa experiência de cárie nos negros, aparentemente foi ultrapassado. Ressaltam o fator dieta, baseados nos experimentos de KEYES ${ }^{z}$ (1960), que em estudos de animais de laboratório demonstrou que mudanças nos fatores ambientais tais como bactérias e dieta, levam ao aparecimento de cárie em ratos que anteriormente eram resistentes a esta lesão.

De nossa parte não poderíamos afirmar se no passado as pessoas não brancas residentes no Brasil apresentavam uma resistência genética ao ataque de cárie, que as fizesse menos susceptíveis que as pessoas brancas, devido à falta de estudos de tal natureza em diferentes áreas do país.
Contudo, encadeando uma série de resultados obtidos no presente estudo, maior percentual de crianças sem cárie, valores médios de cárie menores, média de dentes irrompidos maiores e "risco médio de ataque de cárie por 100 dentes irrompidos" menor nas crianças não brancas, poderíamos pensar na existência desse possível fator genético responsável pela menor susceptibilidade da cárie nelas, mas de certa forma obscurecido, dada a crescente miscigenização que ocorre no Brasil. Poderíamos, também, pensar que o efeito da dieta igual para brancas e não brancas e a frequêencia mínima na ingestão de substâncias açucaradas, pudessem ter contribuido para serem menos elevados os valores de cárie nas brancas, com a conseqüente diminuição das diferenças entre elas e as não brancas, não permitindo evidenciar de maneira marcante, a possível maior susceptibilidade à cárie das primeiras.

\section{CON CLUSOES}

$\mathrm{Da}$ análise dos dados obtidos no presente estudo, ao ser examinado um grupo de 860 crianças brancas e não brancas, de ambos os sexos e residentes em 7 orfanatos do Município de São Paulo, é lícito concluir-se que:

1. os valores médios de cárie nos dentes permanentes são de forma geral maiores para as crianças brancas que para as não brancas. Porém, somente nas idades de 9 e 10 anos para o sexo masculino e de 11 para o feminino as diferenças são significantes (nível 0,05);

2. o número médio de dentes permanentes irrompidos na maioria dos grupos etários é maior para as crianças não-brancas que para as brancas. Porém, somente nas idade de 7,8 e 10 anos para o sexo masculino, as diferenças são significantes (nível $0,05)$; 
CASTELlaNos, R. A. - Aspectos epiđemiológicos da cárle dental em escolares brancos e não brancos de ambos os sexos internos em sete orfanatos da cidade de São Paulo, Brasil, em 1972. Rev. Saúde públ., S. Paulo, 8: 51-62, 1974.

3. a análise estatística dos resultados não permite concluir que exista significantemente uma maior prevalência de cárie dental entre as crianças brancas e não brancas de nosso estùdo por sexo e idade na dentição permanente.

Castellanos, R. A. - [An epidemiological study of dental caries of white and non-white school children of both sexes which are interned in seven orphanages on the city of S. Paulo, Brazil, in 1972. Rev. Saúde públ., S. Paulo, 8: 51-62, 1974 .

SUMMARY: It was realized an epidemiological investigation of dental caries in 860 male and female Brazilians school children, white and non-white from ages 7 to 12 years old, living in 7 orphanages in the city of S. Paulo, Brazil, was conducted to find out whether it was possible to establish, in children living in the same environmental condition, differences in the caries-experience between whites and non-whites. There were controlled very important variables related to the dental carie such as diets and a frequent ingestion of sugar foods during or between meals. There were studied relations among sexes, ages, races and the DMFT, scores as well as the number of the erupted permanent and the mean DMFT for each 100 erupted permanent teeth. Conclusions drawn from the data point out that there are no significant differences of caries-experience in permanent teeth between white and non-white children.

UnIterms: Dental carie*; School children, S. Paulo (Brazil)*; DMFT index *; Epidemiological survey.

\section{REFERENCIAS BIBLIOGRAFICAS}

1. BAGRAMIAN, R, A. \& RUSSELL, A. L - An epidemiological study of dental caries in race and geographic area. J. dent. Res., s0: 1553-6, 1971.

2. BERQUO, E. - Bioestatistica. São Pau10, Faculdade de Higiene e Saúde Pública, 1968.

3. BLAYNEY, J. R. \& HILL, I. N. - Fluorine and dental caries. J. Amer. dent. Ass., 74: 223-302, 1967.

4. CREIGHTON, W. E. - Dental caries experience of negro and caucasian chlldren in Portland, Oregon. $J$. dent. Child., 36: 139-43, 1969.
5. GLICKMAN, I. - The gingiva. In: GLICKMAN, I. - Clinical periodontology. $2^{\text {nd }}$ ed. Philadelphia, Saunders, 1958. p. 9-31.

6. KELLY, J. E. \& SCANLON, J. V. Decayed, missing and fllled teeth among children. Vital Hlth Statist., Series 11 (106): 1-47, 1971.

7. KEYES, P. H. apud BAGRAMIAN, R. A. \& RUSSELL, A. L.

8. KLEIN, H. \& PALMER, C. E. - Dental carles in american indian chlldren. Publ. Hlth. Bull., Washington, (239), 1937. 
CASTEllanos, R. A. - Aspectos epidemiológicos da cárie dental em escolares brancos e năo brancos de ambos os sexos internos em sete orfanatos da cidade de são Paulo, Brasil, em 1972. Rev. Saúde públ., S. Paulo, 8: 51-62, 1974.

9. KNUTSON, J. W. - A index of the prevalence of dental carles in school chlldren. Publ. Hlth. Rep., Washington, 59: 253-63, 1944.

10. LITTLETON, N. W. et al. - Study of differences in the occurrence of dental carles in caucasian and negro children. J. dent. Res., 49: 742-51, 1970 .

11. MANUAL de levantamento da cárie dentária. Săo Paulo, Faculdade de Saúde Pública da USP, 1967.

12. NESTURJ, M. F. - Las razas humanas, Moscu. Progresso, s.d.
13. SEBELIUS, C. L. - Variations in dental caries rates among white and negro children. J. Amer. dent. Ass., 31:544-9, 1944.

14. SOUZA, J. M. P. et al. - Prevalência da cárie dental em brancos e nåo brancos. Rev. Saude puibl., S. Paulo, 1: 38-43, 1967.

15. STEGGERDA, M. \& HILL, J. - Eruption time of teeth among whites, negroes and indians. Amer. J. Orthodont. oral Surg., 28: 361-70, 1942.

is

Recebido para publicação em 14-12-1973. A provado para publicą̧áo em 21-1-1974. 